\title{
Efeito da aplicação de herbicidas dessecantes na soja sobre as populações de nematoides no solo
}

\author{
Soy desiccants herbicides acting in nematode populations on \\ community land
}

\author{
Lucas Baiochi Riboldi1*; ${ }^{*}$ Marineide MendonçaAguillera ${ }^{2}$; Patrícia Andrea Monquero ${ }^{3}$
}

\section{Resumo}

O uso de herbicidas é o principal método de controle de plantas daninhas na cultura da soja. Herbicidas dessecantes também vêm sendo empregados rotineiramente a fim de antecipar a colheita e/ou minimizar a deterioração da qualidade da semente. Existe possibilidade de o contato direto ou indireto com tais defensivos agrícolas, afetarem a comunidade de nematoides no solo. Entretanto, tais efeitos e suas magnitudes ainda estão por ser esclarecidos, especialmente no caso dos herbicidas dessecantes. Assim, o objetivo do trabalho foi avaliar a influência do uso de herbicidas dessecantes em soja sobre os fiotonematoides prejudiciais à cultura. $\mathrm{O}$ experimento foi conduzido com soja transgênica (M-SOY 7908RR. O delineamento experimental foi o de blocos ao acaso com os seguintes tratamentos: paraquat (400 g i.a ha-1), diquat $\left(200 \mathrm{~g}^{-1} . \mathrm{a} \mathrm{ha}{ }^{-1}\right)$, mistura de paraquat e diquat $\left(300+150 \mathrm{~g}\right.$ i.a ha $\left.{ }^{-1}\right)$, duas dosagens de carfentrazone-ethyl (20 g i.a ha ${ }^{-1}$ e $\left.30 \mathrm{~g}^{\text {i.a }} \mathrm{ha}^{-1}\right)$ e testemunha (sem a aplicação de dessecante). A comunidade de nematoides na área foi monitorada em quatro épocas. Em nenhuma dessas épocas foi verificada variação significativa das populações de nematoides prejudiciais à soja, em decorrência da aplicação de qualquer dos dessecantes. Contudo, principalmente na última época de amostragem, a aplicação de dessecante sempre resultou em aumento nas populações de nematoides de vida livre e daqueles considerados parasitas fracos para a soja.

Palavras-chave: Nematoides, Glycine max, glyphosate, aumento populacional

\begin{abstract}
The use of herbicides is the main method of weed control in soybeans. Desiccants are also being used routinely to anticipate the harvest and / or minimize the deterioration of seed quality. There is the possibility of direct or indirect contact with such pesticides, affect the community of nematodes in the soil. However, such effects and their magnitudes are yet to be clarified, especially in the case of selective herbicides. Thus, the objective of this study was to evaluate the use of selective herbicides in soybean on nematodes harmful to the crop. The experiment was conducted with transgenic soybean ('M-SOY 7908RR'). The experimental design was a randomized block design with the following treatments: paraquat (400 g a.i ha-1), diquat (200 g a.i ha- $\left.{ }^{-1}\right)$, a mixture of paraquat and diquat $(300+150 \mathrm{~g}$ a.i $\left.\mathrm{ha}^{-1}\right)$, two doses of carfentrazone ethyl $\left(20 \mathrm{~g} \mathrm{a.i} \mathrm{ha}^{-1}\right.$ and $30 \mathrm{~g}$ a.i ha $\left.{ }^{-1}\right)$ and control (without desiccant application). The nematode community in the area was monitored in four periods. In none of those was found significant variation in the populations of nematodes harmful to soybeans, due to the application of any of desiccants. However, especially in the last sampling time, the desiccant application always resulted in increased populations of free-living nematodes and parasites those considered weak for soybean.
\end{abstract}

Key words: Nematodes, Glycine max, glyphosate, population increase

Discente de Graduação, Universidade Federal de São Carlos, UFSC, campus Araras, SP. E-mail: lucas_riboldi@yahoo.com.br Prof $^{a}$ do Dept $^{\circ}$ de Biotecnologia e Produção Vegetal e Animal, UFSC, campus Araras, SP. E-mail: marineide@cca.ufscar.br Prof $^{a}$ do Dept ${ }^{\circ}$ de Recursos Naturais e Proteção Ambiental, UFSC, campus Araras, SP. E-mail: pamonque@cca.ufscar.br Autor para correspondência 


\section{Introdução}

A soja é de extrema importância econômica para o Brasil. A expansão das áreas de cultivo tem resultado em inúmeras modificações no manejo da cultura, como, por exemplo, o incremento gradual nas aplicações de herbicidas, fungicidas e inseticidas (BELO et al., 2012).

O uso contínuo de produtos químicos em lavouras de soja pode resultar na seleção de organismos resistentes aos mesmos (WEAVER et al., 2007). No caso dos herbicidas, além do efeito supressor ou selecionador de plantas daninhas, também pode haver influência positiva ou negativa dos mesmos sobre os microorganismos e a mesofauna do solo (RIZZARDI et al., 2003).

Os nematoides, assim como os outros organismos do solo, podem ser afetados por substâncias químicas, que, por lixiviação ou por via sistêmica nas plantas, atingem o mesmo (DORAN, 1980; WARDLE et al., 1995).

A ação de produtos fitossanitários sobre os nematoides pode variar em função da espécie e raça do parasita, com a natureza química do produto bem como com a concentração utilizada. Em relação aos nematoides entomopatogênicos, os juvenis infectivos desses organismos, são tolerantes (2-6 horas de exposição) à maioria dos produtos fitossanitários, incluindo herbicidas, fungicidas, acaricidas e inseticidas (ROVESTI; DESEÖ, 1990, citado por NEGRISSOLI JUNIOR, 2005).

Resultados obtidos por Johnson, Dowler e Hauser (1975) indicaram que a aplicação de herbicidas nas culturas de milho, algodão, amendoim e soja não afetou significativamente as populações dos fitonematoides Meloidogyne incognita, Pratylenchus zeae, e P. brachyurus.

Em pesquisa de laboratório, os efeitos do glyphosate, mesmo quando aplicada uma dose três vezes superior à recomendada, sobre a comunidade microbiana do solo foram pequenos e transitórios (WEAVER et al., 2007). Ainda segundo estes mesmos autores, duas aplicações do herbicida em lavoura de soja contendo o gene RR não alteraram a estrutura da comunidade microbiana na rizosfera da soja ou no solo.

De acordo com Yeates et al. (1999), os efeitos dos herbicidas na comunidade de nematoides diferem, dependendo do produto utilizado e do sistema de cultivo. Contudo Liphadzi et al. (2005), conduzindo experimento em dois locais, não encontraram diferença entre as densidades totais de nematoides, entre parcelas tratadas com glyphosate ou com herbicidas convencionais.

Embora o efeito de herbicidas sobre diversos grupos de nematoides já tenha sido objeto de estudo de várias pesquisas, os reais mecanismos dessa relação ainda não são totalmente entendidos (LIPHADZI et al., 2005). Estudos dessas interações se fazem necessários. Assim, o objetivo deste trabalho foi verificar se os herbicidas dessecantes utilizados em soja e o glyphosate tem efeito supressivo ou benéfico para as comunidades de nematoides na cultura da soja.

\section{Material e Métodos}

O experimento foi conduzido no município de Araras, SP, localizado a uma altitude de $629 \mathrm{~m}$, latitude $22^{\circ} 18^{\prime} 00^{\prime}$ 'S longitude 47²3'03' W e que possui, pela classificação de Koppen, clima do tipo Cwa, mesotérmico, com verões quentes e úmidos e invernos secos.

O solo na área do experimental é do tipo Latossolo Vermelho Distroférrico. A soja utilizada foi a cultivar M-SOY 7908RR (Roundup Ready) de ciclo precoce, semeada no inicio de novembro. O delineamento foi o de blocos casualizados com sub-parcelas, formadas por quatro épocas de coleta de amostras (solo e raízes de soja) para análise das populações de nematoides, com quatro repetições. A parcela experimental constou de 10 linhas de soja com $10 \mathrm{~m}$ de comprimento e espaçada em 0,5 $\mathrm{m}$. Como área útil, foram consideradas apenas as 
quatro linhas centrais com $5 \mathrm{~m}$ de comprimento, desprezando-se $2,5 \mathrm{~m}$ em cada extremidade da parcela.

Foram testados os seguintes herbicidas dessecantes: paraquat (400 g i.a ha $\left.{ }^{-1}\right)$, diquat $(200$ g i.a ha-1), diquat + paraquat $(300+150$ g i.a ha $\left.{ }^{1}\right)$ e carfentrazone ethyl (20 e $\left.30 \mathrm{~g}^{\text {i.a ha }}{ }^{-1}\right)$. Estes aplicados no inicio da maturação da soja (estádio R7), utilizando-se pulverizador costal de pressão constante, pressurizado por $\mathrm{CO}_{2}$, com pontas do tipo leque XR 110.02, pressão de 2,0 $\mathrm{kgf} \mathrm{cm}^{-2}$ e volume de calda proporcional a $200 \mathrm{~L} \mathrm{ha}^{-1}$. O glyphosate (testemunha referente à ausência de herbicidas dessecantes) foi aplicado em área total, utilizando o mesmo tipo de pulverizador.

Para determinar as populações de nematoides, foram realizadas avaliações em quatro momentos distintos, durante o período de novembro de 2009 a março de 2010. Na primeira avaliação, antes da semeadura e do estaqueamento da área, foram retiradas da área experimental oito amostras compostas por três sub-amostras de solo, na profundidade de $0-30 \mathrm{~cm}$. Esta avaliação teve como objetivo conhecer a população inicial de nematoides, antes da aplicação dos tratamentos.

$\mathrm{Na}$ segunda avaliação, com as plantas já bem estabelecidas, foram retiradas amostras de solo e raízes das parcelas referentes aos tratamentos. A terceira avaliação constou da coleta de solo e raízes das plantas em cada parcela, um dia após as aplicações dos dessecantes, no estádio R7 da cultura (quando a mesma apresenta vagens amarelas) e a quarta avaliação foi realizada cinco dias após a aplicação dos dessecantes.

Todas as amostras foram encaminhadas para o laboratório de Nematologia da Universidade de São Carlos, imediatamente após a coleta. Neste local as amostras foram mantidas em câmara fria a aproximadamente $8^{\circ} \mathrm{C}$, até o processamento.

Durante a amostragem para verificação de nematoides na área, foi também determinada a umidade volumétrica do solo, realizada pelo método TDR. Dados climatológicos foram obtidos de uma estação presente na Universidade Federal de São Carlos.

Para extração das populações de nematoides do solo e das raízes, foram utilizadas as metodologias da Flutuação Centrífuga em solução de sacarose Jenkins (1964) e Coolen e D’herde (1972), respectivamente. A identificação dos nematoides foi feita ao nível de gênero, utilizando a Chave Classificatória Ilustrada (MAI; LYON, 1975).

As médias dos tratamentos das diferentes variáveis estudadas foram comparadas pelo Teste de Tukey a 5\% de probabilidade.

\section{Resultados e Discussão}

As primeira e segunda coletas de amostras na área foram realizadas apenas para se obter um levantamento e distribuição dos nematoides na área. Foi possível notar tanto a presença de nematoides fitoparasitos como: Meloidogyne sp., Pratylenchus sp., Helicotylenchus sp., Trichodorus sp., Criconemella sp. e também nematoides menos prejudiciais ou não prejudiciais, tais como: Tylenchus sp., Aphelenchus sp., Aphelenchoides sp. e outros gêneros pertencentes à superfamília Dorylaimoidea.

Neste último grupo, estão incluídos nematoides parasitos de outras culturas, e outros dos quais não se conhece o hábito alimentar. Pôde-se notar também uma grande população de nematoides de vida livre nas amostras. Este grupo inclui nematoides que se alimentam de microrganismos do solo e até predadores de outros nematoides, sendo, portanto, um grupo benéfico associado a plantas. A população de nematoides na área se encontrava em número considerável, tendo em vista que não existiam culturas implantadas na época da amostragem. Os nematoides extraídos das amostras e contabilizados se restringiram a formas ativas, juvenis e adultos dos gêneros de ectoparasitos. Haviam ainda aqueles em 
fase de ovos esperando um período mais favorável para a eclosão.Os números de ovos não foram determinados.
Com referência aos nematoides do gênero Meloidogyne, os dados obtidos nas terceira e quarta amostragens estão apresentados na Tabela 1 .

Tabela 1. Números médios de nematoides do gênero Meloidogyne em amostras de 300g de solo e $20 \mathrm{~g}$ de raízes de $\operatorname{soja}^{(\mathrm{I})}$.

\begin{tabular}{lcccc}
\hline \multirow{2}{*}{ Tratamentos } & \multicolumn{3}{c}{ Época de avaliações ${ }^{(I I)}$} \\
\cline { 2 - 5 } Paraquat & Dose $\left(\mathrm{g}\right.$ i.a ha $\left.{ }^{-1}\right)$ & Fevereiro & Março & Médias \\
\cline { 2 - 5 } Diquat & 200 & $135,50 \mathrm{aA}$ & $136,50 \mathrm{aA}$ & $136,00 \mathrm{a}$ \\
Paraquat+Diquat & 400 & $171,75 \mathrm{aA}$ & $225,50 \mathrm{aA}$ & $198,63 \mathrm{a}$ \\
Carfentrazone-ethyl & $300+150$ & $275,75 \mathrm{aA}$ & $184,25 \mathrm{aA}$ & $230,00 \mathrm{a}$ \\
Carfentrazone-ethyl & 20 & $201,00 \mathrm{aA}$ & $89,00 \mathrm{aA}$ & $145,00 \mathrm{a}$ \\
Testemunha & 30 & $168,25 \mathrm{aA}$ & $317,25 \mathrm{aA}$ & $242,75 \mathrm{a}$ \\
Médias & - & $124,50 \mathrm{aA}$ & $102,00 \mathrm{aA}$ & $113,25 \mathrm{a}$ \\
\hline
\end{tabular}

(I) Médias seguidas da mesma letra minúscula na coluna e maiúscula na linha não diferem estatisticamente pelo teste de Tukey, a $5 \%$ de probabilidade. ${ }^{(I I)}$ Avaliações feitas após a aplicação dos dessecantes.

Fonte: Elaboração dos autores.

Como se sabe, a distribuição horizontal dos nematoides no solo é desuniforme, com a formação de reboleiras. Devido a este comportamento natural, existe uma dificuldade nas análises, já que de uma parcela para outra, em um mesmo tratamento, pode variar bastante. Portanto, existe necessidade de se ter um número grande de repetições, para diminuir este efeito.

Os herbicidas dessecantes aplicados no experimento possuem dois tipos de ação: contato direto com a planta e por ação sistêmica. Os herbicidas paraquat, diquat e carfentrazone-ethyl possuem ação de contato e o glyphosate ação sistêmica. O efeito dos herbicidas de contato somente poderia ocorrer sobre nematoides ectoparasitos e de vida livre, já que os mesmos não se translocam na planta. Portanto, nunca entram em contato com os nematoides presentes no interior das raízes, os endoparasitos. Já os herbicidas sistêmicos têm grande probabilidade de agirem nos três grupos de nematoides, por translocação via seiva da planta e também por deriva do produto no solo.
Foi possível observar que a população de Meloidogyne sp. não sofreu acréscimo populacional significativo no período. Nenhum dos tratamentos mostrou diferença significativa a $5 \%$ de probabilidade da testemunha (Tabela 1).

Com relação ao gênero Pratylenchus, foi identificada a espécie $P$. brachyurus, nas amostras da área experimental. Os dados obtidos nas terceira e quarta amostragens sobre este nematoide estão apresentados na Tabela 2. Foi observado uma diferença significativa entre os meses de fevereiro e março, onde houve um decréscimo populacional no período de aproximadamente um mês, podendo-se assim dizer que houve interferência dos tratamentos, na população presente no local do experimento. Os tratamentos que apresentaram efeitos mais acentuados foram paraquat e carfentrazone-ethyl na maior dose, apresentando valores médios populacionais bem próximos.

Em relação aos totais de nematoides fitoparasitos mais prejudiciais, os dados obtidos nas terceira e quarta amostragens estão apresentados na Tabela 3. 
Tabela 2. Números médios de nematoides da espécie Pratylenchus brachyurus em amostras de $300 \mathrm{~g}$ de solo e $20 \mathrm{~g}$ de raízes de soja ${ }^{(\mathrm{I})}$.

\begin{tabular}{lcccc}
\hline \multirow{2}{*}{ Tratamentos } & \multicolumn{3}{c}{ Época de avaliações (II) } \\
\cline { 2 - 5 } & Dose $\left(\mathrm{g}\right.$ i.a ha $\left.{ }^{-1}\right)$ & Fevereiro & Março & Médias \\
\hline Paraquat & 200 & $2961,75 \mathrm{aA}$ & $1004,25 \mathrm{aB}$ & $1983,00 \mathrm{a}$ \\
Diquat & 400 & $2097,00 \mathrm{aA}$ & $2839,00 \mathrm{aA}$ & $2468,00 \mathrm{a}$ \\
Paraquat+Diquat & $300+150$ & $1403,00 \mathrm{aA}$ & $1519,75 \mathrm{aA}$ & $1461,38 \mathrm{a}$ \\
Carfentrazone-ethyl & 20 & $1043,75 \mathrm{aA}$ & $1750,75 \mathrm{aA}$ & $1397,25 \mathrm{a}$ \\
Carfentrazone-ethyl & 30 & $3018,25 \mathrm{aA}$ & $989,25 \mathrm{aB}$ & $2003,75 \mathrm{a}$ \\
Testemunha & - & $2288,50 \mathrm{aA}$ & $860,75 \mathrm{aA}$ & $1574,63 \mathrm{a}$ \\
Médias & & $2135,38 \mathrm{~A}$ & $1493,96 \mathrm{~B}$ & - \\
\hline
\end{tabular}

(1)Médias seguidas da mesma letra minúscula na coluna e maiúscula na linha não diferem estatisticamente pelo teste de Tukey, a $5 \%$ de probabilidade. ${ }^{\text {III }}$ Avaliações feitas após a aplicação dos dessecantes.

Fonte: Elaboração dos autores.

Tabela 3. Números médios de nematoides fitoparasitos mais prejudiciais (Meloidogyne, Pratylenchus, Helicotylenchus, Trichodorus, e Criconemella) em amostras de $300 \mathrm{~g}$ de solo e $20 \mathrm{~g}$ de raízes de soja ${ }^{(\mathrm{I})}$.

\begin{tabular}{lcccc}
\hline \multirow{2}{*}{ Tratamentos } & \multicolumn{3}{c}{ Época de avaliações ${ }^{\text {(II) }}$} \\
\cline { 2 - 5 } & Dose $\left(\mathrm{g} \mathrm{i.a} \mathrm{ha}{ }^{-1}\right)$ & Fevereiro & Março & Médias \\
\hline Paraquat & 200 & $3313,50 \mathrm{aA}$ & $1686,50 \mathrm{aA}$ & $2500,00 \mathrm{a}$ \\
Diquat & 400 & $2457,50 \mathrm{aA}$ & $3447,50 \mathrm{aA}$ & $2952,50 \mathrm{a}$ \\
Paraquat+Diquat & $300+150$ & $1891,00 \mathrm{aA}$ & $2123,25 \mathrm{aA}$ & $2007,13 \mathrm{a}$ \\
Carfentrazone-ethyl & 20 & $1423,75 \mathrm{aA}$ & $2282,50 \mathrm{aA}$ & $1853,13 \mathrm{a}$ \\
Carfentrazone-ethyl & 30 & $3571,50 \mathrm{aA}$ & $1629,00 \mathrm{aA}$ & $2600,25 \mathrm{a}$ \\
Testemunha & - & $2702,50 \mathrm{aA}$ & $2515,50 \mathrm{aA}$ & $2609,00 \mathrm{a}$ \\
Médias & & $2559,96 \mathrm{~A}$ & $2280,71 \mathrm{~A}$ & - \\
\hline
\end{tabular}

(I)Médias seguidas da mesma letra minúscula na coluna e maiúscula na linha não diferem estatisticamente pelo teste de Tukey, a 5\% de probabilidade. ${ }^{\text {(II) }}$ Avaliações feitas após a aplicação dos dessecantes.

Fonte: Elaboração dos autores.

Os fitoparasitos mais prejudiciais são, além de Meloidogyne e Pratylenchus, citados nas Tabelas 2 e 3, outros que apareceram em menor quantidade. Em média, os tratamentos utilizados não mostraram efeitos significativos a $5 \%$ de probabilidade.

A população de Rotylenchulus reniformis foi bem elevada na última amostragem, que pode ser explicado pela baixa incidência desse nematoide na área do talhão, segundo dados de amostragens realizadas ao longo dos anos, o que ocasionou escape de sua obtenção nas amostragens anteriores. Asmus e Schirmann (2004), em seus trabalhos encontraram três reações de cultivares de soja ao nematóide reniforme (Rotylenchulus reniformis). Eles classificaram como resistentes, cultivares de soja onde o nematóide não se multiplicou de forma muito intensa, de susceptibilidade intermediária, quanto houve danos leves nas plantas e de susceptíveis, onde houve grandes danos.

Existem cultivares Monsoy resistentes como o 8001, mas não existe trabalho com o cultivar 7908, já que observações sobre o conhecimento sobre os danos causados por este nematóide são recentes e existem poucos estudos da relação do mesmo com as cultivares e práticas culturais empregadas. Pode-se então perceber, que existe uma grande possibilidade do cultivar plantado ser do grupo daqueles onde o nematóide (Rotylenchulus reniformis) não se multiplica de forma intensa, só chegando a causar danos e a aparecer em grande quantidade (média de 1000 indivíduos por amostra) na quarta amostragem. 
Com referência aos totais de nematoides fitoparasitos menos prejudiciais, os dados obtidos na terceira e quarta amostragens estão apresentados na Tabela 4. Pode-se observar um aumento da população desse grupo de nematoides em todos os tratamentos. Tendo em vista que este grupo abrange nematoides com hábitos alimentares variáveis e para os quais não se dispõe de dados sobre danos à soja, é interessante observar que os tratamentos não apresentaram efeitos deletérios, sendo desta forma, mantida a diversidade na área.

Tabela 4. Números médios de nematoides menos prejudiciais (Tylenchus, Ditylenchus, Aphelenchus e superfamília Dorylaimoidea) em amostras de $300 \mathrm{~g}$ de solo e $20 \mathrm{~g}$ de raízes de soja ${ }^{(\mathbf{I})}$.

\begin{tabular}{lcccc}
\hline \multirow{2}{*}{ Tratamentos } & \multicolumn{3}{c}{ Época de avaliações ${ }^{(I I)}$} \\
\cline { 2 - 5 } & Dose $\left(\mathrm{g}\right.$ i.a ha $\left.{ }^{-1}\right)$ & Fevereiro & Março & Médias \\
\hline Paraquat & 200 & $359,25 \mathrm{aB}$ & $5547,25 \mathrm{aA}$ & $2953,25 \mathrm{a}$ \\
Diquat & 400 & $621,75 \mathrm{aB}$ & $5696,25 \mathrm{aA}$ & $3159,00 \mathrm{a}$ \\
Paraquat+Diquat & $300+150$ & $212,75 \mathrm{aB}$ & $5914,00 \mathrm{aA}$ & $3063,38 \mathrm{a}$ \\
Carfentrazone-ethyl & 20 & $229,25 \mathrm{aB}$ & $5705,75 \mathrm{aA}$ & $2967,50 \mathrm{a}$ \\
Carfentrazone-ethyl & 30 & $322,25 \mathrm{aB}$ & $4357,00 \mathrm{aA}$ & $2339,63 \mathrm{a}$ \\
Testemunha & - & $543,75 \mathrm{aB}$ & $4977,25 \mathrm{aA}$ & $2760,50 \mathrm{a}$ \\
Médias & & $381,50 \mathrm{~B}$ & $5366,25 \mathrm{~A}$ & - \\
\hline
\end{tabular}

(I)Médias seguidas da mesma letra minúscula na coluna e maiúscula na linha não diferem estatisticamente pelo teste de Tukey, a 5\% de probabilidade. ${ }^{\text {(II) }}$ Avaliações feitas após a aplicação dos dessecantes.

Fonte: Elaboração dos autores.

Com referência aos totais de nematoides de vida livre, ou seja, aqueles quenão sealimentam deplantas, os dados obtidos nas terceira e quarta amostragens estão apresentados na Tabela 5. Os nematoides de vida livre tiveram incremento populacional elevado. Pode se observar nas médias, que estes multiplicaram sua população em aproximadamente 8,5 vezes da terceira (fevereiro) para a quarta (março) coleta. A aplicação dos herbicidas paraquat, diquat, paraquat + diquat e carfentrazone-ethyl na dose maior resultaram em aumento significativo na população destes nematoides benéficos. É possível que a microflora como um todo não tenha sido afetada pelos produtos dessecantes citados, o que permitiu que os nematoides que dela se alimentam fossem beneficiados.

Analisando a figura 1, podemos notar um incremento populacional com o aumento da umidade do solo. Entre as terceira e quarta coletas houve uma pequena redução da umidade do solo, porém, como a cultura estava cobrindo toda a área, em seu estádio de máximo crescimento, houve incremento populacional independente dos tratamentos. Sabendo-se que a umidade tem grande influencia sobre o desenvolvimento de nematoides, este seria mais um parâmetro a ser considerado quando se diz respeito a aumento populacional. 
Tabela 5. Números médios de nematoides de vida livre em amostras de $300 \mathrm{~g}$ de solo e $20 \mathrm{~g}$ de raízes de soja ${ }^{(\mathrm{I})}$.

\begin{tabular}{lcccc}
\hline \multirow{2}{*}{ Tratamentos } & \multicolumn{3}{c}{ Época de avaliações ${ }^{(I I)}$} \\
\cline { 2 - 5 } & Dose $\left(\mathrm{g}\right.$ i.a ha $\left.{ }^{-1}\right)$ & Fevereiro & Março & Médias \\
\hline Paraquat & 200 & $513,25 \mathrm{aB}$ & $7828,25 \mathrm{aA}$ & $4170,75 \mathrm{a}$ \\
Diquat & 400 & $1412,25 \mathrm{aB}$ & $8523,50 \mathrm{aA}$ & $4967,88 \mathrm{a}$ \\
Paraquat+Diquat & $300+150$ & $576,00 \mathrm{aB}$ & $8815,50 \mathrm{aA}$ & $4695,75 \mathrm{a}$ \\
Carfentrazone-ethyl & 20 & $826,50 \mathrm{aA}$ & $5298,50 \mathrm{aA}$ & $3062,50 \mathrm{a}$ \\
Carfentrazone-ethyl & 30 & $944,75 \mathrm{aB}$ & $8311,25 \mathrm{aA}$ & $4628,00 \mathrm{a}$ \\
Testemunha & - & $973,25 \mathrm{aA}$ & $5406,25 \mathrm{aA}$ & $3189,75 \mathrm{a}$ \\
Médias & & $874,33 \mathrm{~B}$ & $7363,88 \mathrm{~A}$ & - \\
\hline
\end{tabular}

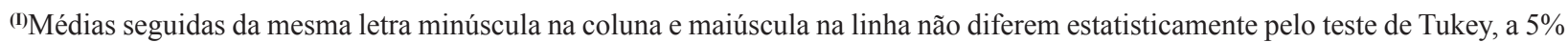
de probabilidade. (II) Avaliações feitas após a aplicação dos dessecantes.

Fonte: Elaboração dos autores.

Figura 1. Relação entre umidade e aumento populacional.

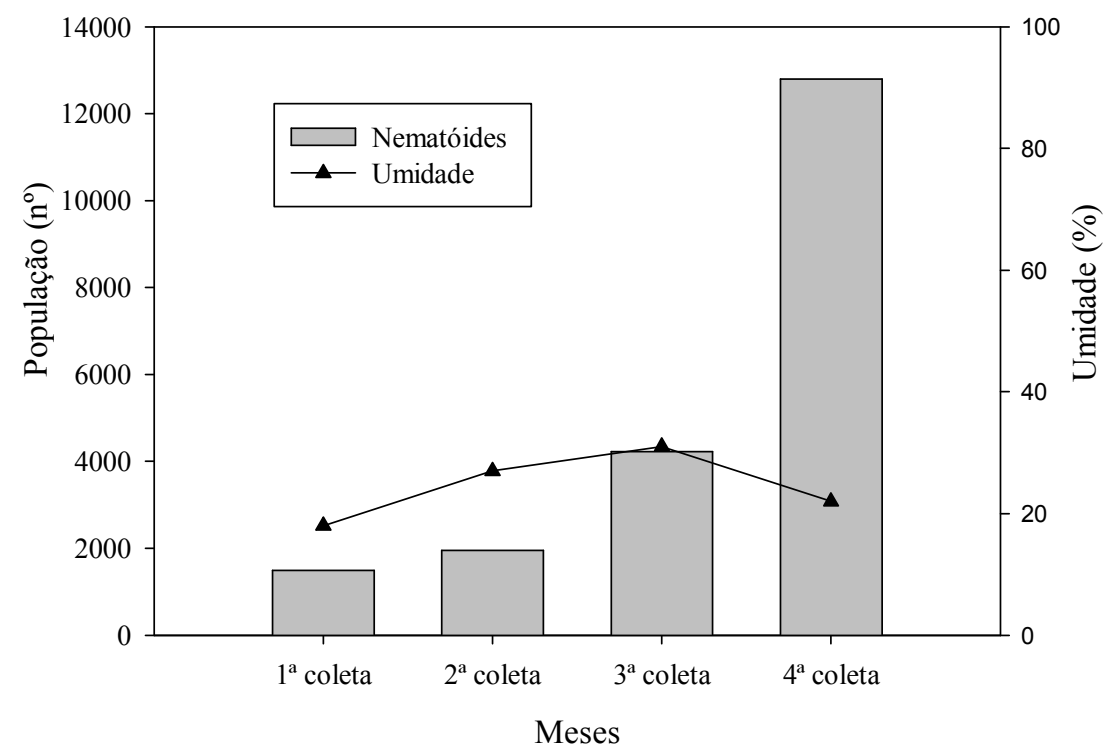

Fonte: Elaboração dos autores.

\section{Conclusões}

Alguns produtos tais como o paraquat e carfentrazone-ethyl na dose maior (30 g i.a ha-1) podem induzir a uma diminuição da população de Pratylenchus. Aplicações dos dessecantes utilizados neste experimento não têm efeitos deletérios sobre nematoides não prejudiciais à soja, inclusive os de vida livre, os quais incluem nematoides benéficos.
Nematoides de vida livre tiveram suas populações aumentadas nos tratamentos paraquat, diquat, paraquat+diquat e carfentrazone-ethyl (30 g i.a ha ${ }^{-1}$ ). Estudos subsequentes são necessários para obtenção de dados mais detalhados sobre efeitos de herbicidas dessecantes aplicados em soja, sobre as comunidades de nematoides associados à cultura. 


\section{Referências}

ASMUS, G. L.; SCHIRMANN, M. R. Reação de cultivares de soja recomendadas no Mato Grosso do Sul ao nematóide reniforme. Nematologia Brasileira, Dourados, v. 28, n. 2, p. 239-240, 2004.

BELO, M. S. S. P.; PIGNATI, W.; DORES, E. F. G. C.; MOREIRA, J. C.; PERES, F. Uso de agrotóxicos na produção de soja do estado do Mato Grosso: um estudo preliminar de riscos ocupacionais e ambientais. Revista Brasileira de Saúde Ocupacional, São Paulo, v. 137, n. 125, p. 78-88, 2012.

COOLEN, W. A.; D'HERDE, C. J. A method for the quantitative extraction of nematodes from plant tissue. Ghent: State Nematology and Entomology Research Station, 1972. 77 p.

DORAN, J. W. Soil microbial and biochemical changes associated with reduced tillage. Soil Science, Madison, v. 44, n. 4, p. 764-771, 1980.

JENKINS, W. R. A rapid centrifugal-flotation technique for separating nematodes from soil. Plant Disease Report. New Brunswick, v. 48, p. 692. 1964.

JOHNSON, A. W.; DOWLER, C. C.; HAUSER, E. W. Crop rotation and herbicide effects on population densities of plant-parasitic nematodes. Journal of Nematology, College Park, v. 7, n. 2, p. 158-168, 1975.

LIPHADZI, K. B.; AL-KHATIB, K.; BENSCH, C. N., STAHLMAN, P. W., DILLE, J. A.; TODD, T.; RICE, C. W.; HORAK, M. J.; HEAD, G. Soil microbial and nematode communities as affected by glyphosate and tillage practices in a glyphosate-resistant cropping system. Weed Science, Stoneville, v. 53, n. 4, p. 536-545, 2005 .
MAI, W. F.; LYON, H. H. Pictorial key to genera of plantparasitic nematodes. London: Comstock Publishing Associate a division of Cornell University Press, 1975. 219 p.

NEGRISSOLI JUNIOR, A. S. Avaliação de técnicas para estudos de compatibilidade de produtos fitossanitários com nematoides entomopatogênicos (Rhabdita: Heterorhabitidae, Sternermatidae). 2005. Tese (Mestrado em Agronomia) - Universidade Federal de Lavras, Lavras.

RIZZARDI, M. A.; FLECK, N. G.; AGOSTINETTO, D.; BALBINOT JUNIOR, A. A. Ação de herbicidas sobre mecanismos de defesa das plantas aos patógenos. Ciência Rural, Santa Maria, v. 33, n. 5, p. 957-965, 2003.

WEAVER, M. A.; KRUTZ, L. J.; ZABLOTOWICZ, R. M.; REDDY, K. N. Effects of glyphosate on soil microbial communities and its mineralization in a Mississipi soil. Pest Manage Science, Stoneville, v. 63, n. 4, p. 388-393, 2007.

WARDLE, D. A.; YEATES, G. W.; WATSON, R. N.; NICHOLSON, K. S. The detritus food-web and the diversity of soil fauna as indicator of disturbance regimes in agro-ecosystems. Plant and Soil, The Hague, v. 170, p. 35-43, 1995.

YEATES, G. W.; WARDLE, D. A.; WATSON, R. N. Responses of soil nematode populations, community structure, diversity and temporal variability to agricultural intensification over a seven-year period. Soil Biology and Biochemistry, Hamilton, v. 31, n. 12, p. 1721-1733, 1999. 